Bangladesh J. Bot. 48(4): 1185-1192, 2019 (December)

\title{
SCREENING OF UPLAND COTTON GENOTYPES (GOSSYPIUM HIRSUTUM L.) AGAINST COTTON VERTICILLIUM (VERTICILLIUM DAHLIAE KLEB.) WILT
}

\author{
SADETTIN ÇELIK, AdEM BARDAK ${ }^{1 *}$ AND OKTAY ERDOĞAN ${ }^{2}$ \\ Department of Forestry, Genç Vocational School, Bingol University, \\ 12500 Genç-Bingol, Turkey
}

Keywords: Upland cotton, Verticillium wilt, Disease severity, Susceptibility

\begin{abstract}
Screening of upland cotton genotypes against Verticillium wilt disease was conducted. The 268 upland cotton genotypes (Carmen and Acala Maxxa cultivar were tolerant- control while cvs. Cukurova 1518 and Acala SJ2 were susceptible-control) were screened against defoliating (PYDV6) and non-defoliating (Vd11) pathotypes of the fungus in a randomized plot design with four replications in growth chamber. Field experiment was established according to the augmented experimental design. Variance analysis was significant $(\mathrm{p} \leq 0.05)$ for all traits against Verticillium wilt. Cvs. Semerkant Uzbek and Taskent 6 were more tolerant than the tolerant-control cultivars against both pathotypes. Most of the genotypes were tolerant in field trial in terms of disease severity that was the lowest for STN K311 genotype in both periods. The highest seed cotton yield was obtained in genotypes as BA119, Okra 204, H-23, Gedera-5, PI 528420 and Acala Royale, which were moderately tolerant to the wilt disease.
\end{abstract}

\section{Introduction}

Cotton (Gossypium spp. L.) is an important industrial plant (Malvales: Malvaceae) which has wide spread use, wide employment opportunity and added value. Cotton fibers are used as raw materials in the textile industry, seeds in the oil sector, seed coat cake after extracting oil in livestock sector, and linter as raw materials in the paper industry (Bolek et al. 2016).

Cotton is grown in 29.816.000 ha area mostly in Asia, and then in America and Africa, and a total of 22.767.000 tons of fiber cotton are produced all over the world (USDA 2017). In Turkey, cotton is cultivated in 501.853 ha area in mainly three regions such as, Southeastern Anatolia, Aegean and Mediterranean Region (Cukurova and Antalya). A total yield of 2.450 .000 tons of seed cotton is produced in these regions (Anon. 2018). Turkey ranks the 7th in the world with $3 \%$ (USDA 2017).

There are biotic and abiotic stress factors limiting the yield in cotton. Verticillium wilt disease, which is caused by Verticillium dahliae Kleb. is the most devastating of biotic stress factors (Alkher et al. 2009). The causal agent can infect about 400 plant species from 40 different families (Joaquim and Rowe 1990). In Adana and Antalya, this rate was at 12 and 4\% while all of Aydın, Izmir and Manisa are experiencing yield loss of $12 \%$ due to Verticillium wilt in Turkey (Çelik et al.2010).

The disease continues its life cycle in three ways as dormant, saprophytic and parasitic. Pathogens can survive for at least 20 years in the soil as microsclerotia $(10-120 \mu \mathrm{m})$ that resist to adverse conditions in the soil (Isaac 1967). In the presence of susceptible host plants microsclerotias induce to germinate with root exudates and enter the plant from the root tips and moves through the xylem preventing the uptake of water and nutrients to the leaves from the roots and creating wilting symptoms in host plants and resulting in large economic losses (Tjamos et al. 2000).

*Author for correspondence: <AdemBardak@ksu.edu.tr>. ${ }^{1}$ Department of Agricultural Biotechnology, Faculty of Agriculture, Kahramanmaraş Sütçü İmam University, 46100 Kahramanmaraş, Turkey. ${ }^{2}$ Department of Organic Farming Business Management, School of Applied Sciences, Pamukkale University, 20600 Civril-Denizli, Turkey. 
The disease is best controlled with crop rotation using balanced fertilization, irrigation and tolerant/resistant cultivars as well as weed control against Verticillium wilt that is not effectively and chemically controlled (El-Zik 1985). However, resistant/tolerant varieties developed against the disease lose their durability over time. For this reason, researchers have reported that breeding trials should be continued to develop resistant varieties (Onan and Karcilıglu 1998).

It has been reported that the number of bolls and yield decreased when the disease symptoms were seen before the first flowering period in cotton, and the effect of the disease on the yield was insignificant if symptoms developed after the first boll opening period (Bejarano-Alcazar et al. 1996). Göre et al. (2004) found that susceptible varieties were more common than tolerant ones, while cvs. Carmen cultivar was tolerant but the remaining genotypes were susceptible or very susceptible. In another study, cotton varieties belonging to Gossypium hirsutum L. were not completely resistant (Galanopoulo 2006). In the study conducted with 13 cotton variety in Kahramanmaraş, the most tolerant variety was cvs. Teks while cvs. GSN-12, St-468, Ayhan 107 and BA 525 were tolerant (Gözcü et al. 2012). Moreover, cvs. Teks, Golda and Carmen were tolerant in terms of disease severity at the boll opening stage and at the end of the harvest in the study conducted to determine the reactions of ten different cotton varieties commonly grown in Diyarbakır against Verticillium wilt (Karademir et al. 2012). Zhao et al. (2014) reported that six upland cultivars, two hybrid lines and four Pima cvs. showed high level of resistance to Verticillium wilt and that these cultivars and lines could be used as parent in breeding programs in the reactions of 223 different cotton genotypes in greenhouse conditions to Verticillium wilt. The lowest disease severity value on cotton plants against defoliant and non-defoliant pathotypes of the fungus in growth chamber was belong to control cvs. Carmen while the highest disease severity value was determined in susceptible control cvs. Cukurova 1518 in a study in which reactions of 13 cotton genotypes to Verticillium was determined (Erdoğan et al. 2015).

The present study was carried out to determine the reactions of upland cotton genotypes $(G$. hirsutum L.) that differ for earliness, yield and fiber quality characteristics to Verticillium wilt disease in growth chamber and field conditions.

\section{Materials and Methods}

A total of 268 upland cotton genotypes ( $G$. hirsutum L.) were used as plant materials, including cvs. susceptible-control Cukurova 1518 and Acala SJ 2 (Erdoğan et al. 2006), cvs. tolerant-control Acala Maxxa and Carmen (Erdoğan et al. 2006), and 264 genotypes developed in different countries with earliness, intermediate and lateness characters found in the germplasm stock of Agricultural Biotechnology Department of Kahramanmaraş Sütçü İmam University. In artificial inoculations, isolates Vd11 (non-defoliating pathotype) and PYDV6 (defoliating pathotype) of $V$. dahliae, that were isolated from cotton and known their virulence levels were used in the study (Erdoğan 2009).

The susceptibility of upland cotton genotypes to $V$. dahliae was determined by the conidial suspension technique in pot trial. The study was carried out in a randomized plot design with four

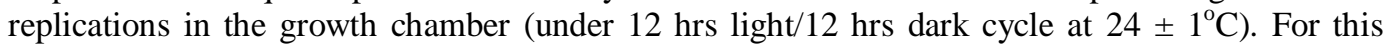
purpose, a mixture soil, sand and peat $(\mathrm{v} / \mathrm{v} ; 1: 1: 1)$ was sterilized in an autoclave at $121^{\circ} \mathrm{C}$ for 1 $\mathrm{h}$, filled with plastic pots $(5 \mathrm{~cm}$ in diameter $)$ and four seeds were sown in each pot. When cotyledon leaves formed, seedlings were tinned to one plant in the pot. V. dahliae cultures having high virulent isolates (Vd11 and PYDV6) were grown on Potato Dextrose Agar (PDA. Difco) for inoculation. After a certain amount of water was added to the Vd11 and PYDV6 isolates, conidia was transferred to the water from the agar surface with a sterile spatula and spore suspension in the flask was filtered with two layers of sterile cheesecloth to remove the mycelium and agar 
particles. $5 \mathrm{ml}$ of spore suspension adjusted to $4 \times 10^{6}$ spores $/ \mathrm{ml}$ with the help of hemocytometer was poured to the bottom parts of each plastic pot $(250 \mathrm{ml})$ and the $4-6$ leaf stage-plants were transferred to plastic pots. Control plants were treated similarly with sterile distilled water. Inoculated and control cotton plants were assessed based on the progression of the disease nearly 3 - 5 weeks after inoculation using a scale of 0 to 5 (0: No symptoms; 1: Chlorosis in lower leaves; 2: Moderate (30-50\% of leaves) wilt with severe chlorosis; 3: Moderate wilt and necrosis; 4: Severe (more than 50\% of leaves) wilt and necrosis; 5: Dead plant) (Tsror et al. 2001). Disease Severity Index (DSI) was calculated by the following formula:

DSI $=[(a \times 0)+(b \times 1)+(c \times 2)+(d \times 3)+(e \times 4)+(f \times 5)] / M$

where $\mathrm{a}, \mathrm{b}, \mathrm{c}, \mathrm{d}$, e and $\mathrm{f}$ refer to the plant number with degree $0,1,2,3,4$ and 5 , respectively. $M$ refers to total plant number.

The field experiment was carried out in Diyarbakır (Bismil)/Turkey in 2016 in a farmer's field, which is naturally contaminated by the non- defoliating pathotype of V.dahliae. The inoculum density of the pathogen in naturally infested field was determined as 16.5 microsclerotia/g (Çokkızgın 2014). In the augmented experimental design, each plot was singlerowed, with a row length of 12 meters, a row spacing of $70 \mathrm{~cm}$, and a row of $20 \mathrm{~cm}$. Cotton seeds were planted with cotton row planter. According to the results of soil analysis, the area of the experiment was rich in organic matter, phosphorus and potassium while the structure was argillaceous, alkaline ( $\mathrm{pH}$ : 7.78) having low salt content and medium lime. Fertilizers were applied as $60 \mathrm{~kg}$ per hectare NPK (20-20-0) before sowing, $60 \mathrm{~kg}$ per hectare ammonium sulphate $(21 \%)$ before the first irrigation and $60 \mathrm{~kg}$ per hectare urea $(46 \%)$ before the second irrigation. When the plants in each plot reached $50-60 \%$ boll opening period in the experiment, foliar evaluations were made using in a scale of 0 - 5 (Tsror et al. 2001) considering chlorosis (yellowness) and necrosis observed in the leaves.

At the end of the harvest, vascular discoloration was determined by cutting the plants in each plot at $10 \mathrm{~cm}$ above soil level and evaluated using the $0-4$ scale (0: There was no browning in the vascular system; 1: Very slight discoloration of woody texture; 2: Brownish pattern scattered throughout the woody texture; 3 : Dark brown staining on all sides of woody texture; 4 : Intense uniform browning and deterioration of woody texture) (Wilhem et al. 1974) according to the color changing of the xylem tissues. DSI was calculated by the following formula:

DSI $=[(a \times 0)+(b \times 1)+(c \times 2)+(d \times 3)+(e \times 4)] / M$

where $a, b, c, d$ and e refer to the plant number with degree $0,1,2,3$ and 4 , respectively. $M$ refers to total plant number.

DSI values were calculated and data were subjected to Arcsin for transformation (Karman 1971). Statistical analyses were performed using JMP statistical software program (5.0.1, SAS Institute, Cary, NC) and the means were grouped by means of the Tukey $(p=0.05)$ test. Seed cotton yield (SCY, kg per hectare) data were recorded from one row of each harvest performed two times by hand.

\section{Results and Discussion}

The analysis of variance results of the characteristics were given in Table 1. Genotypes were significantly different at the $\mathrm{p} \leq 0.05$ level in terms of severity of disease in the growth chamber (defoliating and non-defoliating pathotypes), both $50-60 \%$ boll opening period and harvesting period as well asseed cotton yield in the field experiment (Table 1).

The disease severity values of cotton genotypes for PYDV6 (defoliating pathotype) isolate were higher than Vd11 (non-defoliating pathotype) in the growth chamber (Fig. 1). This can be 
attributed to the high virulence of defoliating pathotype, the rapid spread of the infection, the lack of resistant variety, and the shedding of leaves without any symptom on the leaves (El-Zik 1985). Similar to our findings, researchers have reported that the defoliating pathotype had higher virulence than the non-defoliating one and limits cotton production in almost everywhere of the world (Göre et al. 2007).

Table 1. Analysis of variance for the investigated characters and mean of sum of squares.

\begin{tabular}{|c|c|c|c|c|c|c|c|}
\hline \multirow[t]{2}{*}{ Source } & \multirow[t]{2}{*}{$\mathrm{df}$} & \multirow{2}{*}{$\begin{array}{c}\text { DSI } \\
(50-60 \%)\end{array}$} & \multirow[t]{2}{*}{ DSss } & \multirow{2}{*}{$\begin{array}{c}\text { SCY } \\
(\mathrm{kg} / \mathrm{ha})\end{array}$} & \multirow[t]{2}{*}{$\mathrm{df}$} & \multicolumn{2}{|c|}{$\mathrm{DSpt}$} \\
\hline & & & & & & $\mathrm{Vd} 11$ & PYDV6 \\
\hline Replication (R) & 5 & 0.1851442 & 0.266889 & 3724.56 & 3 & 4.44 & 0.41 \\
\hline Genotype (G) & 3 & $0.3731643 *$ & $0.260272 *$ & $6051.90 *$ & 267 & $0.45^{*}$ & $0.42 *$ \\
\hline Error & 15 & 0.112906 & 0.077914 & 1732.367 & 724 & 0.19 & 0.13 \\
\hline Total & 21 & 0.6712145 & 0.605075 & 11508.827 & 994 & 5.08 & 0.55 \\
\hline
\end{tabular}

*Significant at $\mathrm{p}<\leq 0.05$ probability level; $\mathrm{df}=$ degrees of freedom; DSI $(50-60 \%)=$ Disease severity in leaves at $50-60 \%$ boll opening; DSss $=$ Disease severity in stem section; DSpt $=$ Disease severity in pot trials; $\mathrm{SCY}=$ Seed cotton yield $(\mathrm{kg} / \mathrm{ha})$.

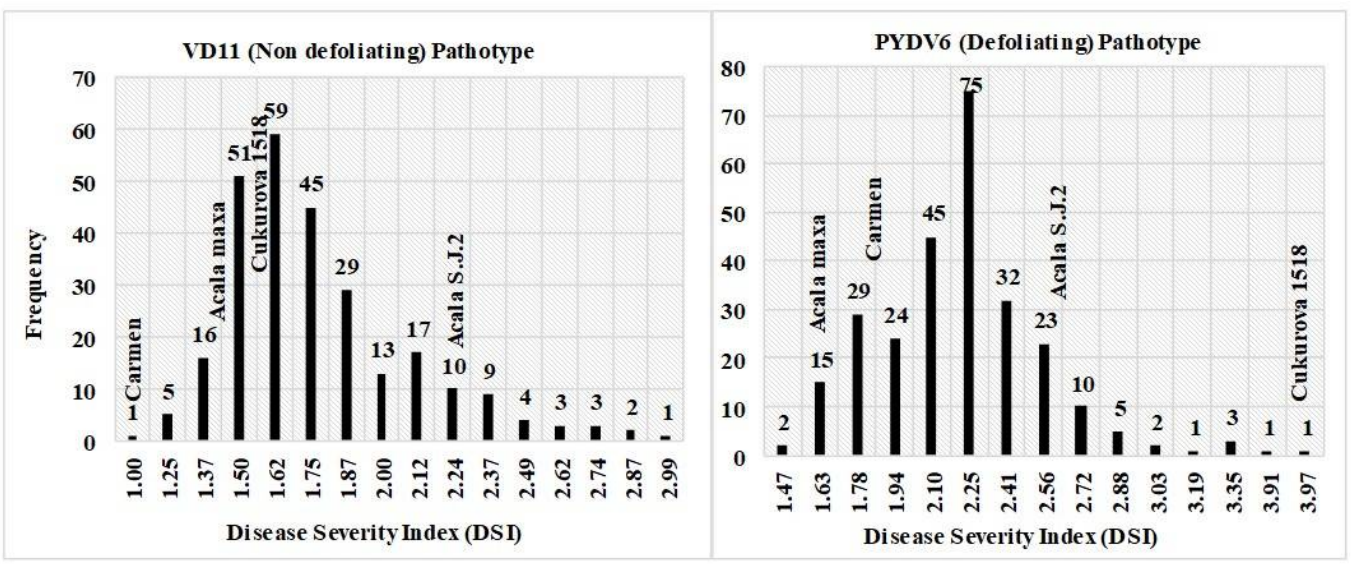

Fig. 1. Frequency of disease severity of upland cotton genotypes against Vd11 and PYDV6 isolates.

One genotype (Sphinx V) was more tolerant than the tolerant control cv. Carmen against Vd11 isolate, followed by genotypes Semerkant Uzbek, Taskent 6, Ujhi 2 Uzbek, DPL 290, Aktas-3, Corina, Delcero and Fibermax 819 in addition to 67 genotypes that were more tolerant than other tolerant control cv. Acala Maxxa. Twenty two genotypes, particularly Flash, BA 811, AB196, BA 440 and Özaltın 404 were more susceptible than the susceptible control cv. Acala SJ2. One genotype (TMN-1) was found to be more tolerant than the tolerant-control cv. Acala Maxxa against the PYDV6 isolate, followed by the genotypes of Semerkant Uzbek, TMN 18, Semu SS7G, Sure grow 404, Tamcot Luxor, Tamcot Pryramid, Taskent-6 and BA 811 while 59 genotypes were more tolerant than tolerant-control cv. Carmen. The highest disease severity value was detected in the susceptible-control cv. Cukurova 1518 while 22 genotypes including mainly Sahel 1, Is 4, Spears 3 (967), PI 173332, Albenia-6172, PI 163615, AB195, Semand 542 and Nazilli M-503 were as susceptible as susceptible-control cv. Cukurova 1518 but 45 genotypes 
were more susceptible than susceptible-control cv. Acala SJ2 (Fig. 1). It has been reported that the Cukurova 1518 and Acala SJ2 varieties are susceptible in high-level to defoliating and nondefoliating pathotypes of the pathogen (Gözcü et al. 2012, Erdoğan et al. 2015). Similar to the data we have obtained, researchers have reported that the difference between the genotypes against the defoliating and non-defoliating pathotypes of the pathogen is significant (Galanopoulo 2006, Erdoğan et al. 2015).

At the stage of the $50-60 \%$ boll opening period in the field, the genotypes Acala 1517-99, Stn K311, Özbek 105, 1118-Glandlesss, Visalia Elmer, Cun S-1, Ab193, GSN 22, Carla, HqculhqpIh-1-95 and Nazilli 954 being at first, 25 genotypes were more tolerant than tolerantcontrol cv. Carmen and 62 genotypes were more tolerant than tolerant-control cv. Acala Maxxa. The highest disease severity value was detected in the susceptible-control cv. Cukurova 1518, while Tamcot Cabcs, Stn 8a, Sphinx V, Is4, Rknr261, Ab114, Semu 55/6, Ca-223, R-5 (Stg-6), Mc Nmara, PI 528525 genotypes were ahead, 12 genotypes were found to be as susceptible as susceptible-control cv. Cukurova 1518. At the end of harvest, 28 genotypes, primarily Stn K311, Dp-388, Tx 0060-2, Tx 0091-1, Hyc-76/59, Flora, Sezener 76, Spnxhqbpis-1-94, Polyester 2379, Zeta 2, Naz 143 and Aydin 110 were more tolerant than tolerant-control cv. Carmen and 37 genotypes were more tolerant than tolerant-control cv. Acala Maxxa. The genotypes Aktaş-3, PI 528426, Sealand 1, Ab162, Gloria, Albania6172, Veremine, PI 528420 and Özbek 142 were found to be more susceptible than susceptible-control cv. Cukurova 1518 while 37 genotypes were more susceptible than susceptible-control cv. Acala SJ2 (Fig. 2). Upland cotton genotypes in the study showed resistance in different levels against Verticillium wilt in both evaluations at 50-60\% boll opening period and stem discoloration, but many genotypes were more tolerant than the tolerantcontrol cvs. Carmen. Similar to the data obtained in the study, researchers reported that the resistance levels of Gossypium species to Verticillium wilt were different and that upland cotton genotypes were as tolerant as the cv. Carmen in infected areas (El-Zik 1985, Erdoğan et al. 2006, Gözcü et al. 2012, Erdoğan et al. 2015).

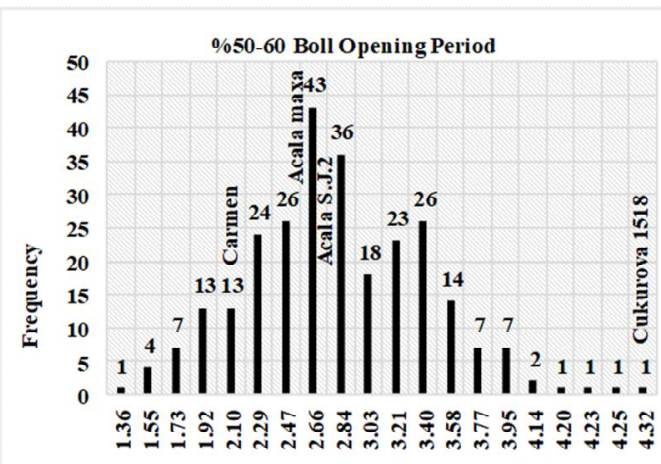

Discase Scverity Index (DSI)

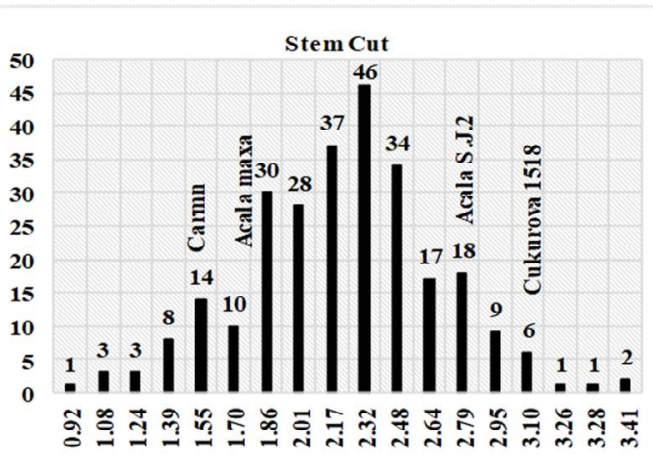

Dis eas e S everity Index (DSI)

Fig. 2. Frequency of disease severity in leaves at $50-60 \%$ boll opening period and in stem section of upland cotton genotypes.

While the difference between genotypes in terms of seed cotton yield was significant, the highest yield values were obtained in BA 119, Okra 204, H-23, Gedera-5, PI 528420 and Acala Royale genotypes. In contrast to the genotypes that were tolerant to Verticillium wilt in current study, moderately tolerant cotton genotypes appeared to be foreground in terms of seed cotton yield (Fig. 3). This could be attributed to the earliness of the genotypes and the time of onset of the disease. Cultural practices and climate factors have also been reported to be effective in disease 
control as well as pathogen effect in the studies carried out (Hutmacher et al. 2005). It is pointed out that the efficiency of the disease infected area is lower by $15.93 \%$ compared to the areas where the disease is less visible (Erdoğan et al. 2006). Similar to findings in our study, researchers have reported that genotypes are highly productive in disease-infected areas due to their early growing characteristics and the possibility of being caught late in the disease (Erdoğan et al. 2015). In contrast to our findings, it has been reported that there is a very significant linear relationship between cotton yield and leaf wilting severity in the studies carried out, and that Verticillium wilt has a relationship with the seed cotton yield in the negative direction (El-Zik 1985).

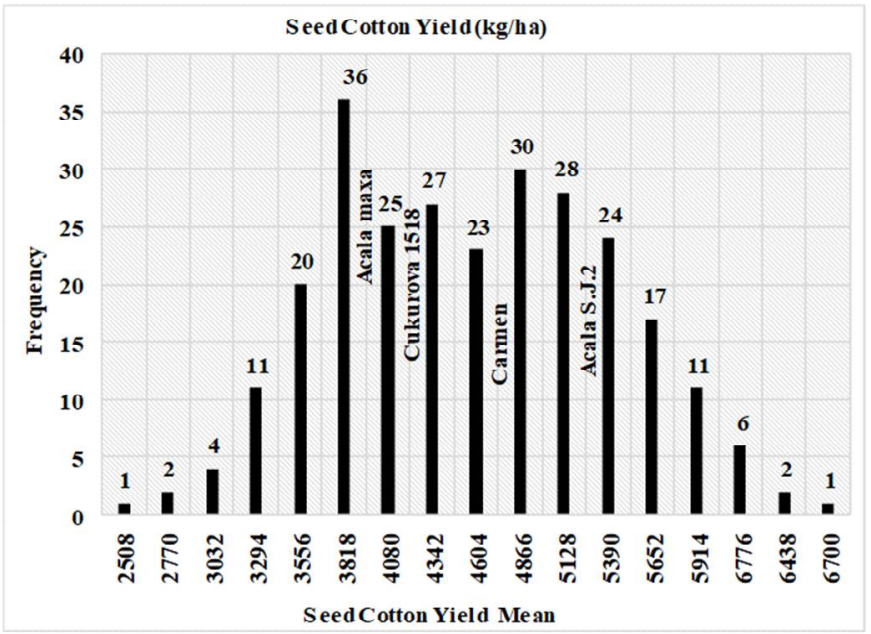

Fig. 3. The frequency of seed cotton yield $(\mathrm{kg} / \mathrm{ha})$ of the upland cotton genotypes.

Verticillium wilt is an important disease-causing loss of yield and quality, which is seen in many cotton growing areas. Recently, defoliating and non-defoliating pathotypes of $V$. dahliae have been found in our country. Defoliating pathotype is more virulent than non-defoliating pathotype. One of the most effective methods against disease that is not controlled by chemicals in an economical way, is to use resistant varieties. Therefore, it is necessary to know the reactions of the parents against two pathotypes of the pathogen and to determine the yield and quality characteristics of the parents to be used for success of the breeding programs for resistance against Verticillium wilt.

In the pot experiments conducted in controlled environment, 71 genotypes against $\mathrm{Vd} 11$ and 44 genotypes against PYDV6 were more tolerant than tolerant-control cvs. Carmen and Acala Maxxa. Against both pathotypes, genotypes Semerkant Uzbek and Taskent6 were found hopeful for breeding programs. In the field experiment, genotypes were different in respect to disease severity evaluations performed in both the $50-60 \%$ boll opening period and the stem section at the end of harvest and many genotypes were more tolerant than the tolerant-control cultivar while the lowest disease severity value was determined in the STN K311 genotype in both periods. This can be attributed to differences in earliness of genotypes and duration of disease infection. Upland cotton genotypes differed in terms of seed cotton yield. BA 119, Okra 204, H-23, Gedera-5, PI 528420 and Acala Royale genotypes, which were moderately tolerant to Verticillium wilt, were the first in terms of seed cotton yield. On the other hand, it should not be forgotten that not only the disease factors but also the cultural practices and climate factors were influential on seed cotton yield. 
As a result, genotypes tolerant to Verticillium wilt will increase their chances of success if they are used as parents in cotton breeding programs. In the meantime, in the case of experiments in which a disease is naturally widespread, it is necessary to carry out detailed studies on both the yield and fiber quality characteristics of the genotypes. Thus, value will be added to the country's economy because the cotton producers use high yielding cotton varieties with better fiber quality characteristics and resistant to Verticillium wilt disease at the same time.

\section{Acknowledgements}

This study is a part of the Sadettin Çelik's postgraduate thesis. Adem Bardak and Oktay Erdoğan are a supervisor. The authors would like to thank the authorities of Scientific Research Project Fund of Kahramanmaraş Sütçü İmam University (Project number: 2017/2-58M) for their financial support and Prof Dr. Kemal Benlioğlu (Adnan Menderes University, Faculty of Agriculture, Aydın, Turkey) for kindly providing PYDV6 isolate.

\section{References}

Alkher H, El Hadrami A, Rashid K, Adam L and Daayf F 2009. Cross-pathogenicity of Verticillium dahliae between potato and sunflower. Eur. J. Plant Pathol. 124: 505-519.

Anonymous 2018. Turkish Statistical Institute, Plant Production Statistical. http://www.tuik.gov.tr. (Accessed on 18.07.2018).

Bolek Y, Tekerek H, Hayat K and Bardak A 2016. Screening of cotton genotypes for protein content, oil and fatty acid composition. J. Agricultural Sci. 8(5): 107-121.

Bejarano-Alc'azar J, Blanco-L'opez MA, Melero-Vara JM and Jim’enez-D'1az RM 1996. Etiology, importance, and distribution of Verticillium wilt of cotton in southern Spain. Plant Dis. 80: 1233-1238.

Çelik İ, Soysal M, İnan Ö, Çetinkaya M 2010. A survey of cotton wilt (Verticillium dahliae) in antalya region. Derim 27(1): 18-32.

Çokkızgın H 2014. Molecular marker improvement and germplasm screening for Verticillium wilt resistance in cotton. Ph.D. (Agril.) thesis, Faculty of Agriculture, University of Kahramanmaraş sütçü İmam, Turkey.

El-Zik KM 1985. Integrated control of Verticillium wilt of cotton. Plant Dis. 1025-1032.

Erdoğan O, Sezener V, Özbek N, Bozbek T, Yavaș G and Ünay A 2006. The effects of Verticillium Wilt (Verticillium dahliae Kleb.) on cotton yield and fiber quality. Asian J. Plant Sci. 5(5): 867-870.

Erdoğan O 2009. Determination of susceptibilities of some cotton breeding lines against cotton wilt disease caused by Verticillium dahliae Kleb. J. Adnan Menderes University Agricultural Faculty 6(2): 9-16.

Erdoğan O, Bolek Y, Dündar H and Bardak A 2015. Screening of cotton genotypes for resistance to Verticillium dahliae Kleb. under greenhouse and field conditions. Romanian Agric. Res. 32: 53-61.

Galanopoulo S 2006. http://www.Ressources.ciheam.org./om/pdf/s14/CI01190.

Göre ME, Dündar H, Erdoğan O, Ekşi İ and Sağdemir A 2004. Investigation on the determination of susceptibility of some cotton varieties against cotton wilt disease caused by Verticillium dahliae Kleb. $1^{\text {th }}$ plant protection congress of Turkey, 8-10 September, Samsun, pp. 161.

Göre ME, Esen H, Bars A, Gözcü D, Altın N and Erdoğan O 2007. Pathotype groups within Verticillium dahliae Kleb. isolates from cotton in Turkey. Anadolu J. AARI 17(1): 16-42.

Gözcü D, Özdemir M and Günaçti HE 2012. Determination of susceptibility of some cotton varieties to Verticillium dahliae Kleb. Caused Verticillium wilt disease in Kahramanmaraş. Plant Protection Bull. 52(2): 135-152.

Hutmacher B, Wright S, Vargas R, Munk D, Marsh B, Davis RM and Ball S 2005. Field check.university of california cooperative extension. Cotton info.ucdavis.edu. /1mages/filed $\% 20$ check.

Isaac I 1967. Speciation in Verticillium. Annual Review of Phytopathology, pp. 201-222. International cotton advisory committee. 2017. http://www.icac.org 
Joaquim TR and Rowe R 1990. Reassessment of vegetative compatibility relationships among strains of Verticillium dahliae using nitrate-nonutilizing mutants. Phytopathol. 80: 1160-1166.

Karademir E, Karademir C, Ekinci R, Baran B and Sagir A 2012. Effect of Verticillium dahliae Kleb. on cotton yield and fiber technological properties. Int J. Plant Prod. 6: 387-407.

Karman M 1971. General information of plant protection and research, testing and evaluation principles of the organization. Regional Plant Protection Research Institute Professional Series Books, BornovaIzmir, $279 \mathrm{~s}$.

Onan E and Karc1lığlu A 1998. Pathotypes of Verticillium dahliae from cotton in Aegean region ve review of Verticillium wilt tolerance in Nazilli 84 cotton. J. Turkish Phytopath. 27: 113-120.

USDA (United States Department of Agriculture), Foreign Agriculture service 2017. Cotton Area, Yield, and Production. http://apps.fas.usda.gov [Accessed on 17.07.2017].

Tjamos EC, Rowe RC, Heale JB and Fravel DR 2000. Advances in Vertcillium Research and Disease Management. APS Press Minesota, USA.

Tsror L, Barak R and Sneh B 2001. Biological control of black scurf on potato under organic management. Crop Protect. 20: 145-150.

Wilhelm S, Sagen JE and Tietz H 1974. Resistance to Verticillium wilt in cotton: source, techniques of identification, inheritance trends and resistance potential of multipline cultivars. Phytopath. 64: 924-931.

Zhao Y, Wang H, Chen W and Li Y 2014. Genetic structure, linkage disequilibrium and association mapping of Verticillium wilt resistance in elite cotton (Gossypium hirsutum L.) germplasm population. PloSone 9(1): e86308.

(Manuscript received on 29 October, 2018; revised on 12 February, 2019) 